\begin{tabular}{|l|l|l|}
\hline \multicolumn{2}{|c|}{ PublisherInfo } \\
\hline \hline PublisherName & $:$ & BioMed Central \\
\hline \hline PublisherLocation & $:$ & London \\
\hline \hline PublisherImprintName & $:$ & BioMed Central \\
\hline \hline
\end{tabular}

\title{
What makes a yeast nuclear pore?
}

\begin{tabular}{|l|l|l||}
\hline \multicolumn{2}{|c||}{ ArticleInfo } \\
\hline \hline ArticleID & $:$ & 3623 \\
\hline \hline ArticleDOI & $:$ & $10.1186 /$ gb-2000-1-2-reports0046 \\
\hline \hline ArticleCitationID & $:$ & reports0046 \\
\hline \hline ArticleSequenceNumber & $:$ & 20 \\
\hline \hline ArticleCategory & $:$ & Paper report \\
\hline ArticleFirstPage & $:$ & 1 \\
\hline \hline ArticleLastPage & $:$ & 4 \\
\hline \hline & & RegistrationDate : 2000-3-27 \\
ArticleHistory & $:$ & Received $\quad$ 2000-3-27 \\
\hline \hline ArticleCopyright & $:$ & BioMed Central Ltd2000 \\
\hline \hline ArticleGrants & $:$ & \\
\hline \hline
\end{tabular}




\begin{tabular}{|l|l|l||}
\hline ArticleContext & $:$ & 130591122 \\
\hline
\end{tabular}

\section{Elena Porro}

\section{Abstract}

A comprehensive analysis has identified and localized all yeast nucleoporins in nuclear pore complexes.

\section{Significance and context}

In eukaryotic cells, nuclei are delimited by the nuclear envelope, which consists of an inner and an outer membrane that join at the nuclear pores. All traffic of cellular materials between the nucleus and the cytoplasm occurs through the nuclear pores. The transport of protein and RNA through the pores is highly regulated by the nuclear pore complex (NPC), a 50-60 MDa assembly of proteins that spans the nuclear pore. The NPC is made up of nucleoporins, or nups, arranged in eightfold symmetry around a cylindrical core that forms a transport channel. The mechanism of transport involves binding of transport proteins - karyopherins or importins/exportins - to the nups, which is regulated by the Ran GTPase. Understanding of the complex interactions contributing to transport requires knowledge of all the proteins in the structure. Rout et al. use a combination of biochemical fractionation, mass spectroscopy, and yeast genome database searching to identify all of the proteins in the yeast NPC. They further map the location of the nups within the structure of the NPC and address their relative stoichiometry.

\section{Key results}

An established protocol was used to obtain nuclear fractions of yeast highly enriched in NPCs. Proteins contained in these fractions were separated by high performance liquid chromatography, and column fractions were separated by SDS gel electrophoresis and protein staining. Each distinct band was excised from the gel, digested with trypsin and analyzed by matrix-assisted laser desorption/ionization time of flight (MALDI-TOF) or MALDI ion trap tandem mass spectroscopy, or by microsequencing. Measured masses or sequences of peptides were used to identify corresponding open reading frames (ORFs) unambiguously from the yeast genome database. The authors claim that, by using large amounts of material and oversampling, they have identified all the proteins in the NPC fraction. To find the nups among the 174 identified proteins, the genes were first genomically epitope-tagged by insertion of a sequence within the genomic DNA that encodes a protein tag that can be identified later with an antibody. This ensured endogenous levels of expression and standardized detection in the subsequent 
characterization. Three criteria were used to determine whether the tagged proteins localized to the NPC: immunofluorescence localization to the nuclear rim; co-localization to the NPC in an NPC clustering assay; and biochemical fractionation to the nuclear envelope. This analysis identified 40 NPC proteins - 29 nups and 11 transport proteins, including three previously uncharacterized ORFs and four known proteins that had not been previously classified as nups. No motor proteins, ATPases, GTPases, or potential gate proteins were found. Further characterization of the nups localized the tagged proteins within the NPC by immunoelectron microscopic mapping onto a higher-resolution structure. Most nups were found on both the cytoplasmic and nuclear faces of the NPC. Two were exclusively nucleoplasmic, three exclusively cytoplasmic and four were found on both sides but showed a consistent bias to one side. Quantitative immunoblots showed that nups fell into three classes of abundance, with most in the middle class present in 16 or 32 copies per NPC.

\section{Links}

This paper is highlighted in the freely available $J$ Cell BiolIn Brief section of the same issue. Peptide masses were assigned to corresponding ORFs using the programs ProFound and PepFrag.

\section{Conclusions}

If this comprehensive analysis of the NPC identified all its components, the minor asymmetry in distribution of nups, as well as the differential localization of RanGTP versus RanGDP, must account for any asymmetry required for transport. The lack of a gate or plug protein suggests that mechanical gating is not required. The authors construct a model for directional nuclear transport based on limited asymmetry and a diffusional channel with a 'virtual' gate.

\section{Reporter's comments}

This paper is as revealing for what it did not find as for what it did. No additional ATPases or GTPases were found. This seems to confirm that no energy system per se (such as GTP hydrolysis) is required for transport and that Ran and the proteins that regulate its nucleotide-bound state are the only regulators necessary for assembly and disassembly of transport complexes. Although there have been reports of electron microscopy showing a protein appearing to plug the pore, in this analysis no gate proteins were found. It is not possible to state categorically whether there is no plug or whether the conditions used by Rout et al. prevented detection of such a protein. But the authors' argument for a 'virtual' gate is compelling. The results confirm the notion that the large size and high symmetry of the complex is due to the presence of 8-32 copies of each protein instead of a large number of different proteins. Only three new proteins were identified. Was all this work worth the trouble for three novel 
proteins? In a word, yes. Three proteins turn out to be $10 \%$ of the total, and knowing that there are no further proteins to find is valuable. For organisms whose genomes have been sequenced, this paper shows how biochemical fractionation can be combined with gene identification and cell biology to elucidate the makeup of large molecular machines.

\title{
Table of links
}

\author{
Journal of Cell Biology \\ J Cell BiolIn Brief section \\ ProFound \\ PepFrag
}

\section{References}

1. Rout MP, Aitchison JD, Suprapto A, Hjertaas K, Zhao Y, Chait BT: The yeast nuclear pore complex: composition, architecture, and transport mechanism. J Cell Biol. 2000, 148: 635-651. 0021-9525

This PDF file was created after publication. 